\title{
Serum levels of leptin receptor in patients with systemic sclerosis
}

\author{
Yukimi Ohyoshi, Takamitsu Makino*, Masatoshi Jinnin, Wakana Nakayama, Satoshi Fukushima, \\ Yuji Inoue, Hironobu Ihn
}

Department of Dermatology and Plastic Surgery, Faculty of Life Sciences, Kumamoto University, Kumamoto, Japan.

\begin{abstract}
Summary Microvascular damage is one of the primary pathologic components of systemic sclerosis (SSc). Serological abnormalities of angiogenic and angiostatic factors in SSc have previously been described. Like these factors, the plasma levels of leptin were significantly elevated in patients with SSc in comparison to normal controls. However, leptin receptor has not been examined in patients with SSc. The current study used sandwich ELISA to evaluate the serum levels of leptin receptor in patients with SSc. Serum samples were obtained from 36 patients with SSc. Samples were also obtained from 12 healthy control subjects and 10 patients with scleroderma spectrum disorder (SSD) who did not fulfill the criteria for SSc but who had the potential to develop SSc. Mean serum leptin receptor levels were significantly higher in patients with SSD than in patients with $\mathrm{SSc}(255.7 \mathrm{ng} / \mathrm{mL}$ vs. $184.6 \mathrm{ng} / \mathrm{mL}, p<0.05$ according to a Mann-Whitney test). There were no statistically significant differences between healthy control subjects and patients with SSc. Clinical parameters were evaluated, and the frequency of esophageal reflux was significantly lower in patients with elevated serum leptin receptor levels than in those with reduced levels $(6.3 \%$ vs. $35.3 \%, p<0.05)$. In summary, these results suggest that the serum levels of leptin receptor are a clinically useful marker of SSD, and measurement of serum leptin receptor over time in patients with SSD may lead to early detection of SSc.
\end{abstract}

Keywords: Leptin receptor, systemic sclerosis, scleroderma spectrum disorder, ELISA

\section{Introduction}

Systemic sclerosis (SSc), or scleroderma, is an acquired disorder that typically results in fibrosis of the skin and internal organs. Although the pathogenesis of SSc is still unclear, it includes inflammation, autoimmune attack, and vascular damage. The condition leads to the activation of fibroblasts and abnormal accumulation of extracellular matrix, mainly in the form of type I collagen $(1,2)$.

Vascular damage is one of the primary pathologic components of SSc. Raynaud's phenomenon, or aberrant nailfold bleeding, is known to be an early vascular event associated with this disease. Telangiectasias, pitting scars, skin ulcers, impaired wound healing, and pulmonary hypertension are frequently observed in

\section{*Address correspondence to:}

Dr. Takamitsu Makino, Department of Dermatology and Plastic Surgery, Faculty of Life Sciences, Kumamoto University, 1-1-1 Honjo, Kumamoto 860-8556, Japan. E-mail: takamitu-makino@fc.kuh.kumamoto-u.ac.jp the disease process and can severely affect the quality of life of these patients. Serological abnormalities of angiogenic and angiostatic factors, including vascular endothelial growth factor, angiopoietin-2, and plateletderived growth factor, in SSc have previously been described; uncontrolled activation of such signaling rather than its inactivation may be the cause of the disturbed vessel morphology in sclerotic skin $(3,4)$.

Significantly increased plasma levels of leptin were also reported in patients with SSc in comparison to normal controls (5). Leptin, the $o b$ gene product consisting of 146 amino acid residues, is known to be secreted by adipocytes (6). Leptin helps to regulate body weight by affecting food intake, energy expenditure, and thermogenesis (7). Furthermore, leptin is involved in many physiological processes, including angiogenesis, by stimulating endothelial cell proliferation (8).

Leptin takes action by binding to its receptor. The leptin receptor usually consists of an extracellular domain and cytoplasmic portion and is restricted to the cell surface. Leptin receptor levels are highest in 
infants, decrease into adolescence, and remain stable throughout adulthood (9). The receptor is expressed predominantly in areas of the hypothalamus, indicating that the leptin receptor also plays an important role in regulating body weight (7). That said, the receptor is also associated with conditions that negatively affect health. The extracellular domain of the receptor can be secreted into body fluid in soluble form. Soluble leptin receptor is found to be up-regulated in patients with obesity as well as in chronic heart failure, end-stage renal disease, and anorexia (10). However, serum leptin receptor levels have not been examined in patients with rheumatic diseases.

The current study posited that leptin signaling contributes to the pathogenesis of vascular damage in SSc and it sought to evaluate the potential for serum levels of leptin receptor to be a useful marker of SSc.

\section{Materials and Methods}

\subsection{Clinical assessment and patient characteristics}

The rheumatic diseases of systemic lupus erythematosus (SLE), dermatomyositis (DM), and SSc as are associated with vasculopathy or dysfunction of endothelial cells were studied. Patients with SSc or SLE fulfilled the criteria proposed by the American College of Rheumatology (ACR) $(11,12)$. SSc was categorized as diffuse cutaneous $\mathrm{SSc}(\mathrm{dcSSc})$ or limited cutaneous SSc (lcSSc) according to the classification system proposed by LeRoy et al. (13). The concept of scleroderma spectrum disorder (SSD) was originally proposed by Maricq et al. to unify typical SSc, early forms of SSc, and closely related disorders, including mixed connective tissue disease (MCTD) $(14,15)$. Ihn et al. later redefined SSD as patients did not fulfill the criteria for SSc but some later developed SSc, so they suggested a new method of diagnosis using a point system to distinguish SSD from early SSc. A total score was obtained as the sum of the following five factors: i) extent of skin sclerosis (maximum, 10 points), ii) pulmonary changes (maximum, 4 points), iii) antinuclear antibodies (maximum, 5 points), $i v$ ) pattern of Raynaud's phenomenon (maximum, 3 points), and $v$ ) nailfold bleeding (maximum, 2 points). A score of 9 or more points is consistent with SSc and a score of 5 to 8 points is consistent with SSD (16). Patients diagnosed with SSD who fulfilled the criteria proposed by Ihn et al. (16) were also included in the current study. Classical DM was diagnosed based on the criteria proposed by Bohan and Peter (17). Clinically and histopathologically typical cutaneous lesions without classical myositis were diagnosed as clinically amyopathic DM (CADM) in accordance with previous criteria $(18,19)$. Clinical and laboratory data reported in the current study were obtained at the time of serum sampling.

\subsection{Measurement of leptin receptor levels}

Levels of serum leptin receptor were measured with a specific ELISA kit (Human leptin receptor, BioVendor Laboratory Medicine, Czech Republic) (20). Briefly, monoclonal anti-human leptin receptor antibodies were precoated onto microtiter wells. Aliquots of serum were added to each well, followed by peroxidase-conjugated antibodies against leptin receptor. Color was developed with hydrogen peroxide and tetramethylbenzidine peroxidase and absorbance at $450 \mathrm{~nm}$ was measured. Wavelength correction was performed based on absorbance at $630 \mathrm{~nm}$. The level of leptin receptor in each sample was determined by interpolation from a standard curve.

\subsection{Statistical analysis}

Statistical analysis was carried out with a MannWhitney test for the comparison of median, and Fisher's exact probability test for the analysis of frequency. A $p$ less than 0.05 was considered significant.

\section{Results and Discussion}

\subsection{Serum levels of leptin receptor in patients with SSc}

Serum leptin receptor levels in patients with various rheumatic diseases and in healthy control subjects are shown in Figure 1. Serum samples were obtained from 36 patients with SSc (13 dcSSc and $23 \mathrm{lcSSc}$ ). Samples were also obtained from 12 healthy control subjects, 10 patients with SLE, 15 patients with DM, 5 patients with CADM, and 10 patients with SSD who did not fulfill the criteria for SSc but who had the potential to develop SSc. Patients with diabetes, obesity, atherosclerosis, or metabolic syndrome and those who had been treated were excluded.

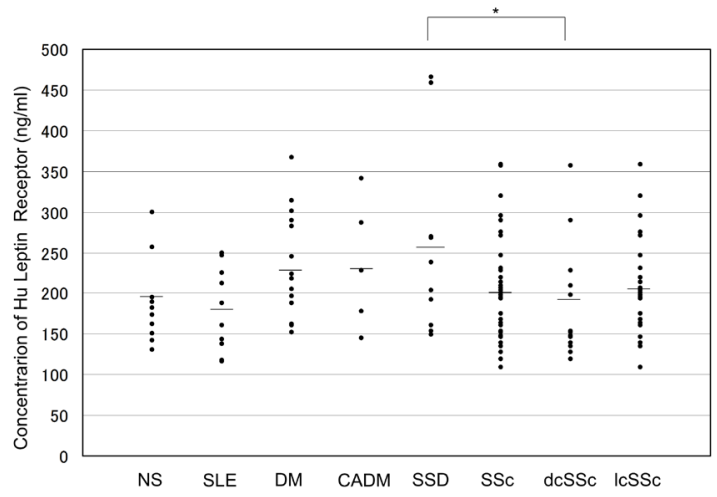

Figure 1. Serum concentrations of leptin receptor in patients with SSc, SSD, SLE, classical DM, CADM, and NS. SSc was classified as dsSSc or 1cSSc. Serum leptin receptor levels were measured with an ELISA kit as described in materials and methods. Serum leptin receptor concentrations are shown on the ordinate. Bars indicate means. A $p$ less than 0.05 is considered significant. 
Mean serum leptin receptor levels were highest in patients with SSD. Although mean leptin receptor levels were elevated in patients with SSD compared to those in patients with SSc or in healthy control subjects, there were no statistically significant differences among the groups. Mean serum leptin receptor levels were significantly higher in patients with SSD than those in patients with dcSSc $(255.7 \mathrm{ng} / \mathrm{mL} v s .184 .6 \mathrm{ng} / \mathrm{mL}, p$ $<0.05$ ). Serum leptin receptor levels may transiently increase in the SSD stage but normalize in the SSc stage. Because progressive tissue fibrosis caused by $\mathrm{SSc}$ is often irreversible, at least clinically, new strategies need to be quickly developed to diagnose patients as early as possible and follow them closely. Accordingly, the concept of SSD should be better understood and characterized. The current findings suggest that elevated serum leptin receptor levels may serve as a useful marker for the differentiation of SSD from SSc. Moreover, patients with SSD frequently have an increased risk of developing SSc in the future. Measurement of serum leptin receptor levels over time in patients with SSD may lead to early detection of SSc. The current study did have one limitation in that it involved a small sample of patients with SSD because SSD is a fairly rare disease. However, the current approach may be a useful way to diagnose SSD. Studies with larger samples are needed in the future.

\subsection{Correlation of serum leptin receptor levels with clinical and serological features of SSc}

Table 1 shows the clinical and laboratory features of $\mathrm{SSc}$ in conjunction with elevated or reduced leptin receptor levels. There were no significant differences between these two groups in term of sex, age of onset, or the prevalence of dcSSc. However, esophageal reflux was significantly less prevalent in patients with elevated serum leptin receptor levels than in those with reduced levels $(6.3 \%$ vs. $35.3 \%, p<0.05)$. As noted earlier, leptin receptor was thought to possibly be involved in the pathogenesis of vascular abnormalities in patients with SSc, but serum levels were not associated with the prevalence of Raynaud's phenomenon, pitting scars, nailfold bleeding, or pulmonary hypertension. Esophageal reflex is treatable and reversible but cannot be detected by serology. Serum leptin receptor may serve as a clinically useful marker. Since patients with SSD had higher leptin receptor levels than both patients with SSc and control subjects and since patients with SSc and elevated serum levels had less esophageal reflux, leptin receptor levels may increase in the very early stage of this disease and thus act to mask the SSc phenotype. However, the exact role of leptin receptor in the pathogenesis of SSc remains unclear. Further studies are needed to clarify these aspects.

In conclusion, mean serum leptin receptor levels were highest in patients with SSD. These results suggest
Table 1. Correlation of serum leptin receptor levels with clinical and serological features in patients with systemic sclerosis (SSc)

\begin{tabular}{|c|c|c|}
\hline \multirow[b]{2}{*}{ Items } & \multicolumn{2}{|c|}{ Serum leptin receptor levels } \\
\hline & $\begin{array}{l}\text { Elevated } \\
(n=18)\end{array}$ & $\begin{array}{l}\text { Low } \\
(n=18)\end{array}$ \\
\hline $\begin{array}{l}\text { Age at the time of serum sampling } \\
\text { (mean years, interquartile range) }\end{array}$ & 63.7 & 59.5 \\
\hline $\begin{array}{l}\text { Duration of disease } \\
\quad \text { (mean years, interquartile range) }\end{array}$ & 102 & 41.3 \\
\hline Type (diffuse: limited) & $6: 11$ & 8:09 \\
\hline MRSS (point) & 8.4 & 13.17 \\
\hline \multicolumn{3}{|l|}{ Clinical features } \\
\hline Pitting scars/ulcers & 41.2 & 50 \\
\hline Nailfold bleeding & 58.8 & 66.7 \\
\hline Raynaud's phenomenon & 88.2 & 92.9 \\
\hline Telangiectasia & 25 & 21.4 \\
\hline Contracture of phalanges & 85.7 & 85.7 \\
\hline Calcinosis & 0 & 12.5 \\
\hline Diffuse pigmentation & 36.4 & 20 \\
\hline Short SF & 69.2 & 81.8 \\
\hline Sicca symptoms & 53.9 & 53.9 \\
\hline \multicolumn{3}{|l|}{ Organ involvment } \\
\hline Pulmonary fibrosis & 29.4 & 44.4 \\
\hline Mean \% VC (\%) & 105 & 97.6 \\
\hline Mean \% DLco (\%) & 89.6 & 84.2 \\
\hline Pulmonary hypertension & 27.9 & 28.3 \\
\hline Oesophagus & $6.3^{*}$ & 35.3 \\
\hline Heart & 37.5 & 17.7 \\
\hline Kidney & 0 & 0 \\
\hline Joint & 50 & 66.7 \\
\hline Thrombosis & 0 & 0 \\
\hline \multicolumn{3}{|l|}{ ANA specificity } \\
\hline Anti-topoI & 22.2 & 33.3 \\
\hline Anti-centromere & 50 & 27.8 \\
\hline Anti-U1 RNP & 16.7 & 16.7 \\
\hline
\end{tabular}

Unless indicated, values are percentages. MRSS: Modified rodnan total skin thickness score; SF: Sublingual frenulum; VC: Vital capacity; DLco: Diffusion capacity for carbon monooxidase; ANA: Antinuclear antibodies; Anti-topo I: Anti-topoisomerase I antibody; Anticentromere: Anti-centromere antibody. ${ }^{*} p<0.05$ versus patients with normal leptin receptor levels according to a Mann-Whitney test.

that elevated serum leptin receptor levels may serve as a useful marker for the differentiation of SSD from SSc and the reduced prevalence of esophageal reflex in SSc.

\section{References}

1. Korn JH. Immunologic aspects of scleroderma. Curr Opin Rheumatol. 1989; 1:479-484.

2. Mauch C, Kreig T. Fibroblast-matrix interactions and their role in the pathogenesis of fibrosis. Rheum Dis Clin North Am. 1990; 16:93-107.

3. Distler O, Distler JH, Scheid A, Acker T, Hirth A, Rethage J, Michel BA, Gay RE, Müller-Ladner U, MatucciCerinic M, Plate KH, Gassmann M, Gay S. Uncontrolled expression of vascular endothelial growth factor and its receptors leads to insufficient skin angiogenesis in patients with systemic sclerosis. Circ Res. 2004; 95:109-116.

4. Davies CA, Jeziorska M, Freemont AJ, Herrick AL. The differential expression of VEGF, VEGFR-2, and GLUT1 proteins in disease subtypes of systemic sclerosis. Hum Pathol. 2006; 37:190-197. 
5. Riccieri V, Stefanantoni K, Vasile M, Macrì V, Sciarra I, Iannace N, Alessandri C, Valesini G. Abnormal plasma levels of different angiogenic molecules are associated with different clinical manifestations in patients with systemic sclerosis. Clin Exp Rheumatol. 2011; 29(Suppl 65):S46-S52.

6. Zhang Y, Proenca R, Maffei M, Barone M, Leopold L, Friedman JM. Positional cloning of the mouse obese gene and its human homologue. Nature. 1994; 372:425432.

7. Tartaglia LA. The leptin receptor. J Biol Chem. 1997; 272:6093-6096.

8. Anagnostoulis S, Karayiannakis AJ, Lambropoulou M, Efthimiadou A, Polychronidis A, Simopoulos C. Human leptin induces angiogenesis in vivo. Cytokine. 2008; 42:353-357.

9. Mann DR, Johnson AO, Gimpel T, Castracane VD. Changes in circulating leptin, leptin receptor, and gonadal hormones from infancy until advanced age in humans. J Clin Endocrinol Metab. 2003; 88:3339-3345.

10. Lahlou N, Clement K, Carel JC, Vaisse C, Lotton C, Le Bihan Y, Basdevant A, Lebouc Y, Froguel P, Roger M, Guy-Grand B. Soluble leptin receptor in serum of subjects with complete resistance to leptin: Relation to fat mass. Diabetes. 2000; 49:1347-1352.

11. Preliminary criteria for the classification of systemic sclerosis (scleroderma). Subcommittee for scleroderma criteria of the American Rheumatism Association Diagnostic and Therapeutic Criteria Committee. Arthritis Rheum. 1980; 23:581-590.

12. Hochberg MC. Updating the American College of Rheumatology revised criteria for the classification of systemic lupus erythematosus. Arthritis Rheum. 1997; 40:1725.
13. LeRoy EC, Black C, Fleischmajer R, Jablonska S, Krieg T, Medsger TA Jr, Rowell N, Wollheim F. Scleroderma (systemic sclerosis): Classification, subsets and pathogenesis. J Rheumatol. 1988; 15:202-205.

14. Maricq HR, Weinrich MC, Keil JE, Smith EA, Harper FE, Nussbaum AI, LeRoy EC, McGregor AR, Diat F, Rosal EJ. Prevalence of scleroderma spectrum disorders in the general population of South Carolina. Arthritis Rheum. 1989; 32:998-1006.

15. Maricq HR, McGregor AR, Diat F, Smith EA, Maxwell DB, LeRoy EC, Weinrich MC. Major clinical diagnoses found among patients with Raynaud phenomenon from the general population. J Rheumatol. 1990; 17:1171-1176.

16. Ihn H, Sato S, Tamaki T, Soma Y, Tsuchida T, Ishibashi Y, Takehara K. Clinical evaluation of scleroderma spectrum disorders using a points system. Arch Dermatol Res. 1992; 284:391-395.

17. Bohan A, Peter JB. Polymyositis and dermatomyositis (first of two parts). N Engl J Med. 1975; 292:344-347.

18. Euwer RL, Sontheimer RD. Amyopathic dermatomyositis (dermatomyositis siné myositis). Presentation of six new cases and review of the literature. J Am Acad Dermatol. 1991; 24:959-966.

19. Sontheimer RD. Cutaneous features of classic dermatomyositis and amyopathic dermatomyositis. Curr Opin Rheumatol. 1999; 11:475-482.

20. Buyan N, Ozkaya O, Bideci A, Söylemezoğlu O, Cinaz P, Gönen S, Kalman S, Bakkaloğlu S, Hasanoğlu E. Leptin, soluble leptin receptor, and transforming growth factor- $\beta 1$ levels in minimal change nephrotic syndrome. Pediatr Nephrol. 2003; 18:1009-1014.

(Received March 28, 2013; Revised April 15, 2013; Accepted April 19, 2013) 